\title{
A Biblioteca nos tempos e espaços digitais: novos e antigos desafios ${ }^{1}$
}

\author{
Luiz Percival Leme Britto
}

\begin{abstract}
Graduado em Letras e Doutor em Linguística pela Unicamp. Professor do Instituto de Ciências da Educação da Universidade Federal do Oeste do Pará.
\end{abstract}

http://dx.doi.org/10.1590/1981-5344/2276

o presente trabalho - desenvolvido na forma de ensaio examina as possibilidades de convivência entre a biblioteca e os processos de comunicação de base digital. Para tanto, primeiramente analisam-se as implicações daquilo que vem se chamando de cultura digital para a formação cultural individual e social, destacando os limites e os equívocos conceituais e práticos consequentes do fascínio da tecnologia e da banalização do conhecimento; num segundo momento, apresentam-se as bases de uma política pública de biblioteca efetivamente democrática.

Palavras-chave: Biblioteca pública. Cultura digital. Formação. Conhecimento. Política.

\section{The library in digital spaces and times: old and new challenges.}

The present study - developed in the form an essay examines the possibilities of coexistence between the library and the communication processes of digital basis. To do so, first we analyze the implications of what has been called digital culture for personal and social cultural development, highlighting the limits and the conceptual and practical misunderstandings that result from the fascination of technology and trivialization of knowledge; following this, we present the foundations of an effective democratic public policy in library.

\footnotetext{
${ }^{1}$ Este texto resulta da fusão de dois outros textos - A Biblioteca e a cultura digital: que diálogo é esse? e Breves apontamentos sobre o papel das bibliotecas públicas -, apresentados à comissão especial para a discussão da política da Red de Bibliotecas de la Alcaldía de Bogotá, Colômbia, em outubro de 2013.
} 
Keywords: Public library. Digital culture. Education. Knowledge. Politics

Recebido em 19.11.2014 Aceito em.20.11.2014

\section{Biblioteca e conhecimento na era digital}

Que relação se pode estabelecer entre a biblioteca, em particular da biblioteca pública, com o que se vem chamando de cultura digital?É razoável prever a extinção da biblioteca ou sua simples transformação em espaço virtual? Restam-lhe funções culturais e formativas nas novas condições de realização da cultura e da economia na sociedade capitalista?

Não é assunto simples ou óbvio, como se suporia à primeira vista. Ao contrário, é um tema complexo, cuja consideração pode, conforme se desenvolva a análise, levar a decisões que só tenderão a fragilizar a biblioteca, esvaziando-a de seu papel formativo.

Numa perspectiva crítica, de quem não se entusiasma com as novidades eletrônicas nem vê nelas anúncio necessário de liberdade interessa, especialmente indagar como as novas formas de expressão, comunicação e acesso à informação e ao conhecimento se refletem nas práticas de leitura e nos modos de produção, circulação e apropriação do conhecimento.

Ou, pensando mais diretamente na formulação de políticas estruturantes das bibliotecas públicas, examinar de que modo se podem incorporar as novas dimensões e manifestações de cultura consequente das novas disponibilidades técnicas na organização e funcionamento da biblioteca. Isso porque paira no ar a ideia de que a cultura digital implica uma nova relação com o conhecimento que prescindiria do livro, pelo menos em seus moldes tradicionais, e das formas de pensar que se fazem com ele.

Essa estranha ideia decorre da observação impressionista das expressões mais atuais de cultura, com base no fato de que se tem amplamente afirmado por estudiosos de diferentes áreas que a conectividade geraria novos processos de conhecimento, de subjetividade e de relacionamento com a cultura, processos nunca vistos na história humana e que implicariam o início de uma nova era, sobrepujando o que se entende como a era do livro.

Aquilo que se tem chamado de cultura digital, que inclui desde o uso de aparelhos de comunicação móvel com acesso a internet até as artes virtuais e os processos de colagem e reprodução eletrônica, ganhou enorme visibilidade e sugere que todas as formas de ser e de viver na sociedade experimentam radical e velocíssima transformação.

De fato, o mundo moderno experimentou enormes transformações nos últimos cinquenta anos em função principalmente da chamada revolução microeletrônica, com destaque, por um lado, para a reestruturação produtiva, o rearranjo no mercado de capital e a 
financeirização da economia e, por outro, para a expansão qualitativa e quantitativa dos meios de comunicação e informação.

Não há como desconsiderar as novas e enormes possibilidades de processamento, armazenamento e transferências de dados oferecidas pelos sistemas computacionais, assim como não se pode negligenciar a informatização e automatização dos processos, que trouxeram consequências enormes para todas as dimensões da vida cotidiana. A criação da web e das plataformas de interação online - uma das expressões mais evidentes dessa revolução - dá a impressão de conectividade universal e imediata, com a intensa participação universal. Ademais, a explosão das redes sociais, blogs e sites e sua presença em processo de comunicação, educação e política dão a impressão de um significativo avanço da participação social em dimensões essenciais da ordem do poder, como na organização de movimentos de contestação, na luta pelos direitos humanos e na influência decisiva em eleições dos mandatários das grandes potências mundiais.

Tais transformações não poderiam deixar incólumes as formas de realização da cultura, da informação e do acesso ao conhecimento. Há que cuidar, contudo, com a análise ligeira e conclusões precipitadas e demasiado definitivas. Assim, as dinâmicas contemporâneas têm implicado, de forma difusa e desigual, a emergência de outros protagonistas no cenário político e cultural, com relativa possibilidade de se fazerem ouvir vozes de povos tradicionais e de grupos marginais, antigos e novos - frutos da própria precarização da vida cotidiana em função da reestruturação produtiva e da reorganização do capital.

Aparentemente estes segmentos, que nunca tiveram acesso efetivo aos bens culturais e materiais da sociedade capitalista, estariam tendo a chance de mostrar-se e de contestar a cultura hegemônica. E, para se fazer ver e ouvir, os novos protagonistas produzem formas de expressão e comunicação próprias e originais, produtos que ganham dimensões maiores quando reverberados na WEB, nas redes sociais e em espaços alternativos. Alijados do que se convencionou chamar de cultura escrita, produzem uma espécie de contracultura oral ou digital ou, ainda, no caso dos povos tradicionais, reafirmam as formas seculares de conhecimento.

Isso significa uma mudança no panorama histórico, com a relativa emergência de novos atores na cena cultural e política. Contudo, é um grave equívoco teórico e político supor que tais processos de produção cultural e intelectual sejam simplesmente um movimento de contraposição à cultura hegemônica convencional e que sua legitimação possa se realizar pela negação do conhecimento formal ou pela neutralização das diferenças. Essa concepção, aparentemente democrática e progressista, apenas contribui para a manutenção das diferenças e a restrição do acesso a porções essenciais da cultura universal.

As novidades parecem ser menores do que predicam os áugures digitais. O que se verifica, para além das mudanças resultantes da incorporação das novas tecnologias, é a radicalização da desigualdade e da exclusão da ordem do conhecimento e do poder efetivo por meio da massificação e banalização dos valores e das formas de acesso ao 
conhecimento, com a pseudodesvalorização da formação intelectual formal.

Vale a pela a advertência de Claudia Weber Abramo, realizada já em meados dos anos de 1990:

Sob o ponto de vista da distribuição do poder, nada autoriza a concluir que a "revolução da informação" atue na direção de um maior equilíbrio entre os agentes sociais. A informação como instrumento de poder não pode ser medida absoluta, mas relativamente: como o poder é atributo relacional, não advém da "posse" de uma quantidade $X$ de informação, mas (entre outras coisas, naturalmente) do fato de A dispor de mais condições de processar a informação do que $B$. (ABRAMO, 1995, p. 3)

Ademais, diferentemente do que se apregoa, a escrita não perdeu importância; ao contrário, tornou-se muito mais significativa e determinante, especialmente quando se consideram as formas de inserção na vida social e nos processos de organização da cotidianidade. O alfabetismo não somente não desapareceu com a revolução microeletrônica, como, pelo contrário, passou a ser o metro principal de inclusão na ordem social. A ordem digital é uma expressão da própria cultura escrita, expressão que, como todas as outras, que a ressiginifica e amplia suas possibilidades.

A globalização da economia e a reestruturação produtiva, com base na acumulação flexível do capital, engendraram um processo produtivo em constante mudança, com a incorporação da ciência e da tecnologia em função da competitividade constitutiva do próprio sistema. Assim, a complexidade atual dos processos produtivos e do funcionamento do setor de serviços, próprios da organização do capitalismo posterior à revolução microeletrônica pressupõe demanda um trabalhador que saiba ler, seguir instruções e lidar com problemas de tipos variados, o que significa saber operar sistemas normativos que não se aprendem nas relações domésticas e no cotidiano imediato. A cotidianidade e o senso comum, por sua vez, adquiriram no mundo tecnológico formulações mais complexas e se organizam, em grande parte, por valores e condutas que se definem verticalmente e exigem níveis maiores de alfabetismo.

A imposição do alfabetismo como condição de participação social é um processo inelutável que vem ocorrendo ininterruptamente desde o século XIX. Todos os estudos da área demonstram a clara correlação entre conhecimento, leitura e da escrita e inserção social. E a razão principal desse fenômeno são as formas de organização do capitalismo, com intensa urbanização e industrialização da agricultura.

Contudo, é mister observar que, se por um lado, as referidas transformações nos processos de produção e de organização social aumentam a importância do alfabetismo e da instrução formal, por outro, o aumento da instrução média da população não apenas não tem tido como correlato mais democracia e mais distribuição da riqueza. O que ocorre é a banalização do conhecimento e a instituição de um modelo de 
cultura que se limita à reprodução de normas, valores e procedimentos, pouco oferecendo o acesso a bens culturais acumulados pela humanidade.

O que se evidencia é a realização de um alfabetismo pragmático aquele que permite à pessoa ler e escrever umas tantas coisas e operar com números, de modo a agir apropriadamente em função dos protocolos e procedimentos de produção e consumo. "E não mais do que isso parece ser necessário para a obtenção dos fins a que se destina: leitor de um universo tranquilo que tem de ser o seu, sua escrita se inscreve nas práticas que servem a esse universo" (OSAKABE, 1984, p. 151). E esse tipo de alfabetismo, não apenas está muito próximo daquilo que se tem chamado de oralidade, como não contribui para a formação autônoma e a ação intelectual livre dos sujeitos.

Portanto, sob o véu de uma suposta ampliação de direitos e possibilidades e de diversidade de expressão de ideias e valores, o que ocorre é a radicalização das dimensões entorpecentes e apaziguadoras da cultura e a vulgarização de modelos ideológicos que escamoteiam as formas como se realiza o poder, dentre as quais se destaca um multiculturalismo anódino e unidirecional. $O$ que aparenta ser reconhecimento de cultura se manifesta muitas vezes como interdição.

Enfim, é preciso reconhecer que, se é fato que as novas tecnologias e os novos modos de comunicação e de expressão que permitem, assim como os processos de produção que se instauraram com a revolução microeletrônica, supõem um sujeito ágil e que aprende na prática e na diversidade, é fato também que, limitados a estes espaços, os sujeitos não disporão de conhecimentos que contribuam para a crítica a essa mesma e nova condição de alienação. Como observa Acácia Kuenzer, em seus estudos sobre trabalho e educação no mundo contemporâneo,

a prática, por si não ensina, a não ser através da mediação da ação pedagógica. São os processos pedagógicos intencionais e sistematizados, portanto, que mediando as relações entre teoria e prática, ensinarão a conhecer. Não basta, portanto, inserir 0 trabalhador na prática, para que ele espontaneamente aprenda. (...) As novas demandas de articulação entre conhecimento científico e conhecimento tácito reforçam a escolarização em níveis cada vez mais ampliados e com maior qualidade como condição necessária à inserção e permanência nas relações sociais e produtivas para os que vivem do trabalho. Não se trata, contudo, de retroceder a práticas pedagógicas teoricistas, de longa data questionadas, mas também não há como sustentar o pragmatismo utilitarista que tem se traduzido em práticas pedagógicas espontaneístas com frequência cada vez maior. Trata-se, portanto, de repensar os processos pedagógicos, para que a escola de fato estabeleça a mediação entre conhecimento e práticas sociais, entre teorias e práticas, de modo a intencionalmente assumir a sua função de introduzir os homens e mulheres nas ações relativas ao conhecer e ao 
produzir conhecimentos, tácitos e científicos, tendo em vista a construção de uma outra sociedade, sobre bases mais justas e igualitárias. (KUENZER, 2003, p. 65)

A perspectiva de uma formação cultural emancipadora e democrática obriga a reconhecer que a informação fácil apoiada no senso comum não estimula a indagação da condição humana nem a crítica e a criatividade desimpedida. Ao contrário, mantém a pessoa na alienação e na submissão ao que se estabeleceu desde outro lugar, oferecendo-lhe a falsa ilusão de crescimento e liberdade.

Visto sob essa ótica, tomado como um absoluto, o modo de realização de cultura que emerge da expansão da comunicação digital constitui um processo tipicamente alienante em que impera a ideologia da subjetividade egoísta e autossuficiente. Desprovida de generacidade e universalidade, a cultura torna-se pseudocultura. A "alienação quando ocorre um abismo entre 0 desenvolvimento humano-genérico e as possibilidades de desenvolvimento dos indivíduos humanos, entre a produção humano-genérica e a participação consciente do indivíduo nessa produção" (HELLER, 2004, p. 39-40).

É nessa perspectiva que se recorre à análise de Adorno sobre a indústria cultural, evidenciando o quanto há, ainda, de novos e mais profundos processos de reificação e de massificação que culminam na produção de um ambiente que impede a formação efetiva e a emancipação dos sujeitos. Com isso, escreve Adorno (1996, p. 389-395),

Apesar de toda ilustração e de toda informação que se difunde (e até mesmo com sua ajuda) a semiformação passou a ser a forma dominante da consciência atual, o que exige uma teoria que seja abrangente. (...) No clima da semiformação, os conteúdos objetivos, coisificados e com caráter de mercadoria da formação cultural, perduram à custa de seu conteúdo de verdade e de suas relações vivas com o sujeito vivo, o qual, de certo modo, corresponde à sua definição. (...) O semiculto transforma, como que por encanto, tudo que é mediato em imediato, o que inclui até o que mais distante é. Daí a tendência à personalização: as relações objetivas se transformam em pessoas singulares e de pessoas singulares se espera a saúde. Seu culto delirante avança com a despersonalização do mundo.

Ademais, a vertigem informativa e comunicacional que se estabeleceu na lógica do consumo digital faz com que a informação seja ao mesmo tempo imprescindível e inútil. Estar desconectado ou ignorante do que acontece nas redes sociais é como estar for a do mundo, não obstante a conexão não implicar nenhum conhecimento relevante. Novamente pode-se recorrer a Adorno, cuja análise antecede a própria emergência da cultuar digital: 
A semiformação, enquanto consciência alienada, não sabe da relação imediata com nada, senão que se fixa sempre nas noções que ela mesma aporta às coisas. Sua postura é a do takingsomething for granted, e seu tom repete um cansativo "Como, você não sabe isso?", especialmente nas conjunturas mais desenfreadas.

Para além do saber imediato, pode-se postular outra esfera de realização cultural, relacionada com práticas intelectuais mais densas e sistemáticas. Trata-se dos modos de conhecimentos e valores formais, relacionados com a instrução e o estudo. Por essa esfera circulam textos cuja forma e cujos conteúdos transcendem o automatismo e o pragmatismo, tendendo à autorreferenciação e à descontextualização, implicando maior nível de metacognição e o desprendimento do pensamento prático e imediato. Nessa esfera, em diferentes formas e níveis, encontram-se as produções que se operam nas ciências, na literatura, na filosofia, enfim, as produções humanas mais orgânicas e sofisticadas.

A análise que aqui se desenvolve obriga reconhecer que a biblioteca não pode abdicar de sua função precípua de lugar de encontro com e desenvolvimento do conhecimento. Certamente, as bibliotecas continuaram incorporando em seus sistemas gerenciais as possibilidades que oferece a tecnologia; mais ainda: tratarão de ampliar a acessibilidade aos acervos por meios digitais, locais e remotos. E tratarão de criar novos e desafiadores espaços para o estudo e a reflexão sobre as produções culturais inovadoras. E buscarão criar as pontes legítimas e necessárias entre as expressões populares e formas de conhecimento que transcendem o imediatismo. Tudo isso, contudo, não modifica em nada a relação essencialmente o estudante e o texto, entre o leitor e o livro. Pois essa é a essência e a razão de ser das bibliotecas.

\section{Apontamentos sobre o papel das bibliotecas públicas}

Com base na análise acima apresentada, cabe indagar quais seriam os papéis essenciais da biblioteca pública nesse tempo de comunicação e informação virtuais, especialmente para quem assume uma postura política que valoriza o desenvolvimento intelectual das pessoas e a possibilidade de uma formação que transcenda o imediatismo e o consumismo.

É razoável assumir, como ponto de partida, que a função precípua da biblioteca é a promoção de leitura, entendida como a oferta qualificada de textos, especialmente aqueles que encerram elementos fundamentais da formação intelectual e que, normalmente, por estarem além do senso comum, não encontram outros espaços de circulação e de atividades com eles relacionadas.

Nessa perspectiva, sem muito risco de escapar àquilo que tradicionalmente se estabeleceu como histórico da biblioteca, podem-se 
identificar quatro funções que Ihes são próprias, as quais se realizam deforma distinta em cada unidade, conforme seu lugar na rede de serviço e seu vínculo local: 1. o acolhimento e a guarda organizada da produção cultural e intelectual humana (literatura/arte, história ciência, política, etc.) que se realiza e circula por meio da escrita (enfim, o que normalmente se entende como acervo); 2. o registro documental da produção cultural, política e social da comunidade, da cidade e da nação o que corresponde ao que chamamos de memória; 3. a disseminação do conhecimento e da arte, principalmente daqueles que são próprios da cultura escrita; e 4 . a promoção de práticas culturais e intelectuais relacionadas com o livro e a leitura; a isso tem sido tradicionalmente identificado como promoção da leitura.

Estas funções não são estanques. Ao contrário, se inter-relacionam de tal forma que as decisões concernentes às duas primeiras imbricam-se com as duas últimas de tal forma que é sua inter-relação que oferecerá dinamismo e densidade à organização do acervo e à produção e registro da memória. Em termos claros e exatos, a constituição do acervo e a organização da memória estão a serviço da disseminação do conhecimento e da formação cultural.

A questão que naturalmente se apresenta, definidos os objetivos principais, é: que ações estratégicas realizar para alcançá-los?

Para responder minimamente essa questão, há que reconhecer que a biblioteca pública tendeu historicamente a realizar-se conforme as necessidades e os interesses de uma parte pequena da sociedade exatamente aquela que sempre deteve o poder político, econômico e cultural. Mesmo que aberta a todos, a biblioteca tomava suas decisões e organizava-se de tal modo que somente grupos de pessoas conformados por uma ordem cultural determinada e afeitos a ela podiam efetivamente usufruir de seus serviços. A maioria da gente - fosse por falta de instrução, fosse por falta de identidade, fosse até pela dificuldade objetiva de acesso - não se incluía (e ainda não se inclui) no público usuário.

Mais recentemente, com a diversificação dos objetos de cultura escrita - muitos dos quais articulados com o cotidiano urbano -, a massificação da educação e a ampliação das exigências deformação laboral, a biblioteca passou a ser uma possibilidade de formação popular. Contudo, premida pelo pragmatismo, massifica-se sem democratizar-se, pouco contribuindo para o acesso ao conhecimento diferenciado e para a oferta de uma formação que, ao mesmo tempo, compreenda e transcenda a cotidianidade e o imediatismo.

O que se verifica é que a necessidade de responder a demandas imediatas e a submissão a critérios de avaliação fundamentados na lógica da eficiência e da produtividade, bem como a ânsia por popularização, têm instado as bibliotecas a investir mais fortemente em atividades utilitárias, que a afastam de sua missão principal, descuidando-se do papel de disseminação da cultura, produção e registro de memória e de formação cultural.

Neste sentido, o grande desafio quando se busca constituir uma rede pública de bibliotecas está em promover o avanço da democracia ao 
invés da massificação do atendimento. Trata-se de assumir que a biblioteca não apenas presta serviços, mas tem também um papel de protagonista na disseminação e desenvolvimento do conhecimento e na constituição de uma política cultural democrática. E isto significa que, mais que oferecer entretenimento cultural, investir em formação aligeirada ou reproduzir práticas massificadas de produção e consumo de cultura - não importa o quanto isso seja atrativo -, cabe à biblioteca realizar ações problematizadoras da cultura e da política que estão além do panorama imediato e das razões comezinhas da vida cotidiana.

Chauí (2008, p. 66), analisando a questão política da produção cultural e a função do Estado democrático nesse processo, sustenta que

uma política cultural definida pela ideia de cidadania cultural, em que a cultura não se reduz ao supérfluo, entretenimento, aos padrões do mercado, a oficialidade doutrinaria (que é ideologia), (...) se realiza como direito de todos os cidadãos, direito a partir do qual a divisão social das classes ou a luta de classes possa manifestar-se e ser trabalhada porque no exercício do direito a cultura, os cidadãos, como sujeitos sociais e políticos, se diferenciam, entram em conflito, comunicam e trocam suas experiências, recusam formas de cultura, criam outras e movem todo o processo cultural.

É particularmente importante atentar para o fato de que métodos de aproximação pedagógica só têm valor se não descaracterizam o objeto e o objetivo formativo. A leitura fácil de entretenimento domingueiro, sem que façam as devidas articulações culturais, pode alcançar sucesso de público, mas não contribui para o avanço efetivo da disseminação e da formação cultural.

Por outro lado, há que cuidar para que a biblioteca não se constitua como expressão de poder alienígena. Isso supõe uma opção política que considera a legitimidade da cultura e dos sabres locais e a radical ressignificação dos valores da cultura e da política hegemônicas, por meio do diálogo constante com as diversas formas de expressão e do questionamento dos processos de produção e circulação do conhecimento. Por isso, as decisões estratégicas de organização de acervo, produção de memória, disseminação do conhecimento e formação cultural tem de afastar-se tanto do elitismo próprio da ordem dominante como do populismo simplório de reprodução do óbvio (que também é resultado da ordem dominante).

Objetivamente, há que considerar tanto para o sistema como para cada localidade: 1. a oferta organizada das obras relevantes para a comunidade de forma acessível - o que implica indagar em que tipo de acervo se deve investir, considerando a necessidade formativa e as demandas locais, sempre lembrando que a demanda se cria e não apenas se atende; 2. a instituição de dinâmicas e instrumentos de investigação e registro documental, de forma que a história não seja apenas a história 
oficial; 3. a promoção da formação de grupo de leitores de modo a ampliar o universo de referencia se de experiências de leitura, especialmente daqueles que não se promovem em outros espaços sociais e nos meios de comunicação de massa; 4. a criação de dinâmicas de estudo do conhecimento acumulado pela humanidade e, ao mesmo tempo, de produção de conhecimento novo e de memória local, instigando à ação intelectual reflexiva e crítica, e ao registro escrito desse produto; 5. o desenvolvimento contínuo de ações de formação intelectual e cultural, considerando os diversos públicos assistidos, numa perspectiva que, sem ser elitista ou pragmática, valorize a experiência da leitura por meio do livro; e, finalmente,6. a divulgação da cultura universal e local, por meio de sessões públicas de leitura e de outras artes e saberes, conformadas em função do perfil dos usuários.

De modo a cumprir apropriadamente essa tarefa, a biblioteca (pensada enquanto sistema) necessita, além de um corpo funcional técnica e intelectualmente preparado para as funções que lhe cabem, de uma política institucional que contemple: 1 . a constituição permanente de acervo que se determine não apenas pela demanda local ou pelo número de consultas, mas crucialmente pela crítica cultural e pedagógica; 2 . o estímulo à produção e ao registro da memória - patrimônio cultural, intelectual e político da nação e de cada uma de suas regiões, localidades e comunidades -, incluindo oficinas, seminários, recolha de depoimentos e guarda de documentos; 3 . a capacitação funcional continuada, contribuindo para a emergência e o desenvolvimento de líderes locais; e 4. a formação pública, incluindo I. a promoção de estudos e pesquisas para o desenvolvimento individual e coletivo, II. o estímulo permanente de atividades cultural e intelectual e III ações diversificadas de disseminação da cultura - promoção da leitura.

Claro que isso não se faz em gabinete nem se imagina como marco zero. A razão de ser de cada pequena biblioteca que compõe uma rede e das bibliotecas maiores de referência está diretamente relacionada com o reconhecimento do que já está constituído e em funcionamento e com a valorização daqueles que estão aí atuando e trabalhando, bem como no estabelecimento de vínculos fortes com as lideranças sociais e comunitárias.

Se o que se quer é contribuir para o desenvolvimento das comunidades, tem-se, acima de tudo, que se definir as políticas. E uma política pública de biblioteca deve, para ser efetivamente democrática, ao invés de buscar ajustar-se às demandas imediatas e pragmáticas que se colocam no âmbito da cultura, da política e da economia, investir profundamente na possibilidade de acesso à informação e ao conhecimento que não está evidente nem se põe como algo que se absorve imediata e facilmente.

\section{Referências}

ABRAMO, Claudia Weber. Irracionalismo e informação. Folha de S. Paulo, 12 jun. 1995, p. 3. 
ADORNO, Theodor W. Teoria da Semicultura. Educação e Sociedade, n. 56, ano XVII, p. 388-411, dez. 1996.

CHAUÍ, Marilena. Cultura e democracia. Crítica y emancipación: Revista latino-americana de Ciencias Sociales, Buenos Aires, Año 1, n. 1, p. 5376, jun. 2008.

HELLER, Agnes. História e cotidiano. São Paulo: Paz e Terra, 2004.

KUENZER, Acácia. As relações entre conhecimento tácito e conhecimento científico a partir da base microeletrônica: primeiras aproximações. Educar, Curitiba, Especial, 2003, p. 43-69.

OSAKABE, Haquira. Considerações em torno do acesso ao mundo da escrita. In: ZILBERMANN, Regina. A leitura em crise na escola: as alternativas do professor. Porto Alegre: Mercado Aberto, 1984. p. 147152. 